\title{
FITOTECNIA
}

\section{VIABILIDADE DE USO DO HÍBRIDO HAWAII 7996 COMO PORTA-ENXERTO DE CULTIVARES COMERCIAIS DE TOMATE ${ }^{(1)}$}

\author{
SUANE COUTINHO CARDOSO ${ }^{(2)}$; ANA CRISTINA FERMINO SOARES ${ }^{(3)}$; ALEXSANDRO \\ DOS SANTOS BRITO $^{(4)}$; LÉA ARAÚJO DE CARVALHO ${ }^{(3)}$; CARLOS ALBERTO DA SILVA LEDO ${ }^{(5)}$
}

\begin{abstract}
RESUMO
A técnica de enxertia é utilizada em algumas hortaliças, principalmente em áreas infestadas, para atribuir resistência a patógenos do solo, minimizando as perdas de produção de cultivares suscetíveis. Este trabalho teve como objetivo avaliar o desenvolvimento e a produtividade de plantas de tomateiro enxertadas em híbrido, tido como resistente a Ralstonia solanacearum, em comparação a pés-francos. O experimento foi desenvolvido em viveiro (produção de mudas e enxertia) e em céu aberto, no município de Cruz das Almas, Bahia, no período de outubro de 2003 a fevereiro de 2004. Utilizou-se o método de enxertia de fenda cheia, com o híbrido 'Hawaii 7996' como porta-enxerto e as cultivares Santa Clara, Santa Cruz Kada e Débora Plus, suscetíveis a R. solanacearum, como enxerto. O delineamento experimental foi em blocos ao acaso, com seis tratamentos ( 3 enxertados e 3 pés-francos), 5 repetições e 6 plantas por parcela útil. Avaliaram-se os caracteres: diâmetro do caule, altura da planta e da primeira inflorescência, distância entre inflorescências e produtividade comercial de frutos. O desenvolvimento das plantas, a produção total e a massa média dos frutos foram semelhantes para os tratamentos enxertados em relação a seus respectivos pés-francos e não houve incompatibilidade entre porta-enxerto e enxerto. A cultivar Santa Cruz Kada foi mais sensível às condições agroecológicas do município de Cruz das Almas, refletindo negativamente na produção e no peso médio dos frutos. Observou-se na enxertia com o híbrido 'Hawaii 7996' potencial para viabilizar a produção de tomateiros comerciais suscetíveis à murcha bacteriana, em áreas infestadas com $R$. solanacearum.
\end{abstract}

Palavras-chave: Lycopersicon esculentum, Ralstonia solanacearum, enxertia, fenda cheia, Hawaii 7996.

$\left({ }^{1}\right)$ Parte da dissertação de mestrado da primeira autora. Recebido para publicação em 25 de setembro de 2004 e aceito em 28 de novembro de 2005.

$\left({ }^{2}\right)$ Mestranda em Ciências Agrárias, Escola de Agronomia, Universidade Federal da Bahia, UFBA, 44380-000 Cruz das Almas (BA). Bolsista CAPES.

$\left(^{3}\right)$ Departamento de Fitotecnia, UFBA, Cruz das Almas (BA).E-mail: acsoares@ufba.br

$\left({ }^{4}\right)$ Graduando em Agronomia, Escola de Agronomia, UFBA. Bolsista PIBIC.

$\left({ }^{5}\right)$ Embrapa Mandioca e Fruticultura, Caixa Postal 07, 44380-000 Cruz das Almas (BA). E-mail: ledo@cnpmf.embrapa.br 


\title{
ABSTRACT \\ POTENTIAL OF HAWAII 7996 HYBRID AS ROOTSTOCK FOR TOMATO CULTIVARS
}

\begin{abstract}
Grafts have been used in horticultural crops, to overcome soilborne plant pathogens, and thus minimize yield losses of susceptible cultivars. This work aimed at to evaluate growth and yield of tomato plants grafted on to a hybrid resistant to Ralstonia solanacearum, as compared to non-grafted seedlings. Seedling production and grafting were done in nursery and grafted plants essayed Cruz das Almas, State of Bahia, Brazil, from October of 2003 to February of 2004. Cleft graft was used on to Hawaii 7996 hybrid as rootstocks, and 'Santa Clara', 'Santa Cruz Kada' and 'Débora Plus', susceptible to the disease were used as scion. The experimental design was a completely randomized blocks with six treatments and five replicates ( 3 scion-rootstock combinations and 3 types of non-grafted seedlings). The following characteristics were evaluated: stem diameter, plant and first inflorescence height, distance between inflorescences and commercial fruit yield. Plant growth, average fruit weight and yield did not differ between grafted treatments and non-grafted seedlings. There was no incompatibility between the rootstock and the scion plants. 'Santa Cruz Kada' showed more sensitivity to the agroecological conditions of Cruz das Almas, which reflected negatively in the yield and average fruit weight. The hybrid 'Hawaii 7996' is a promising rootstock allowing the growth of tomato crop bacterial wilting susceptible cultivars, in areas infested with $R$. solanacearum.
\end{abstract}

Key words: Lycopersicon esculentum, Ralstonia solanacearum, grafting, Hawaii 7996.

\section{INTRODUÇÃO}

A técnica da enxertia em hortaliças de frutos é utilizada nas famílias Solanaceae e Cucurbitaceae, com o objetivo de conferir-lhes resistência aos patógenos do solo, baixa temperatura, seca, excesso de umidade e aumento da capacidade de absorção de nutrientes. Apesar de ser muito utilizada na produção comercial de mudas de hortaliças em países como Japão, Holanda e Espanha, é uma técnica de uso recente no Brasil (PeIL, 2003). Produtores paulistas de pepino japonês já adotam a enxertia como alternativa de produção para reduzir as perdas ocasionadas por fungos do solo e nematóides (CAÑIZARES e Goto, 1999).

A murcha bacteriana causada pela bactéria de solo Ralstonia solanacearum é uma das doenças do tomateiro que pode ser controlada com o uso da enxertia (GómEZ, 1997). Essa bacteriose pode causar perdas variáveis até de $100 \%$ na produção, sendo considerada uma das doenças mais importantes do tomateiro (LOPES, 1994). Seu controle é extremamente difícil, principalmente devido à ampla gama de hospedeiros, alta variabilidade genética e sobrevivência do patógeno no solo por longos períodos (TAKATSU et al., 1984; REIFSCHNEIDER e TAKATSU, 1985). As principais medidas preconizadas para o controle da murcha bacteriana incluem ações preventivas ou práticas culturais visando impedir ou retardar o aparecimento da doença na cultura (SILVEIRA et al., 1996).

Como alternativa de controle de patógenos radiculares, a enxertia em solanáceas como tomate, berinjela e pimentão e cucurbitáceas, tais como pepino, melão e melancia, tem sido bastante utilizada
(KAWAide, 1985; Gómez, 1997). A enxertia envolve a união de partes de plantas por meio da regeneração de tecidos, na qual a combinação resultante atinge a união física que lhe permite desenvolver como uma única planta. Para tanto, é necessário que o tecido cambial do enxerto e porta-enxerto estejam em íntima associação, para que o tecido possa formar uma conexão contínua (CAÑIZARES, 1998). Esse método, que envolve a utilização de uma cultivar comercial suscetível sobre um porta-enxerto resistente, pertencente à outra cultivar, espécie ou gênero da mesma família botânica, tem como finalidade evitar o contato da planta sensível com o patógeno, mantendo o sistema radicular sadio, possibilitando a realização das funções normais de absorção de água e nutrientes do solo (PeIL, 2003).

Em ensaios onde se avalia a enxertia como controladora de doenças de solo a produtividade aumenta quando são utilizados porta-enxertos adequados, em relação às plantas não enxertadas (LimA et al., 2000).

Na região do Recôncavo Baiano, a murcha bacteriana tem inviabilizado o cultivo do tomateiro e outras solanáceas em áreas de pequenos produtores, que, em sua maioria, não dispõem de outras áreas de plantio e buscam alternativas para o controle dessa doença. A técnica da enxertia surge como um método viável para a utilização de cultivares comerciais suscetíveis ao patógeno, para minimizar as perdas na produção. Este trabalho teve como objetivo avaliar a viabilidade de uso do híbrido Hawaii 7996, resistente a $R$. solanacearum, como porta-enxerto de cultivares comerciais de tomate do grupo Santa Cruz. 


\section{MATERIAL E MÉTODOS}

O experimento foi desenvolvido no viveiro do Departamento de Fitotecnia da Escola de Agronomia da UFBA e no campo na Fazenda Santo Agostinho, localizados no município de Cruz das Almas, BA, a $12^{\circ} 40^{\prime} 19^{\prime \prime}$ de Latitude Sul e $39^{\circ} 06^{\prime} 22^{\prime \prime}$ de Longitude Oeste de Greenwich, tendo $220 \mathrm{~m}$ de altitude (AlmeIDA, 1999). O clima é tropical quente e úmido, Aw a Am, segundo a classificação de Köppen. A temperatura e a umidade médias registradas no período de avaliação, de outubro de 2003 a fevereiro de 2004, foram de $24,77^{\circ} \mathrm{C}$ e $78,40 \%$ respectivamente.

Como porta-enxerto utilizou-se o híbrido Hawaii 7996, resistente à murcha bacteriana, obtido do Asian Vegetable Research and Development Center (AVRDC) em Taiwan (JAUnet E WANG, 1999). Como enxerto foram utilizadas três cultivares do grupo Santa Cruz, suscetíveis a R. solanacearum: Santa Clara e Santa Cruz Kada e o híbrido Débora Plus (CARDoso, 2004).

\subsection{Produção de mudas de tomateiro}

Para a produção das mudas, utilizou-se como substrato uma mistura de Plantmax ${ }^{\circledR}$ e areia lavada, na proporção 2:1 (v:v). As mudas do porta-enxerto (híbrido Hawaii 7996) foram produzidas em sacos pretos de polietileno $(7,0 \mathrm{~cm} \times 18,5 \mathrm{~cm})$ com $500 \mathrm{~mL}$ de substrato e as mudas dos enxertos ('Santa Clara', 'Santa Cruz Kada' e 'Débora Plus'), em copos descartáveis com $300 \mathrm{~mL}$ de substrato, 8 a 10 dias após a semeadura do porta-enxerto. As mudas a serem utilizadas como testemunhas pés-francos ('Santa Clara', 'Santa Cruz Kada' e 'Débora Plus') foram semeadas no mesmo dia da semeadura do portaenxerto, também em sacos de polietileno $(500 \mathrm{~mL})$, contendo o mesmo substrato.

A enxertia foi realizada em porta-enxertos com 5 a 6 folhas verdadeiras (30 dias após semeadura) e o enxerto com 3 a 4 folhas verdadeiras (20 dias após semeadura), conforme descrito por YAMAKAWA (1982). O método utilizado foi fenda cheia, que consiste em seccionar transversalmente o porta-enxerto acima da segunda folha verdadeira, seguida da abertura de uma fenda com profundidade de $1,5 \mathrm{~cm}$ e o enxerto foi seccionado com um corte tipo cunha, acima das folhas cotiledonares, deixando de 3 a 4 folhas verdadeiras. Os cortes para enxertia foram feitos com um bisturi, desinfetado com álcool $70 \%$ após cada enxertia. Utilizaram-se para o amarrio fitas do plástico Parafilm $\mathrm{M}^{\circledR}$ (American National Can, Neenah, WI), as quais, pela sua elasticidade, permitiram melhor união e proteção do ponto de enxertia, rompendo-se espontaneamente após o intumescimento do caule, em virtude da cicatrização, facilitando a retirada após o pegamento e evitando injúrias à planta.

Após a enxertia, as plantas foram mantidas em câmara úmida, em viveiro com luminosidade de $50 \%$. A estrutura da câmara úmida teve as seguintes características: duas bancadas de madeira com 1,0 m de largura, 3,0 $\mathrm{m}$ de comprimento, 0,80 $\mathrm{m}$ de altura e $0,50 \mathrm{~m}$ entre bancadas, cobertas com plástico transparente preso em armação em arco com 1,20 m de altura, feita com tubo PVC $1 / 2$ polegada. As bancadas foram cobertas com plástico preto e jornal, colocandose também copos descartáveis com água, espalhados entre as plantas, com o objetivo de manter a umidade do ar em torno de $90 \%$. As mudas enxertadas permaneceram na câmara úmida por 10 dias e durante esse período foi feito o arejamento da câmara, com o levantamento das laterais do plástico transparente e mantida a umidade relativa do ar ideal, borrifando as plantas e molhando o jornal quatro vezes ao dia.

No quinto dia após a enxertia, as mudas foram adubadas com $50 \mathrm{~mL} /$ muda de solução nutritiva de Hoagland e no décimo dia, o plástico transparente foi retirado, deixando-se as mudas apenas com o tela de sombreamento de $50 \%$ para aclimatação.

\subsection{Experimentação}

O delineamento experimental foi em blocos ao acaso, com seis tratamentos e cinco repetições, sendo a parcela útil composta por seis plantas. Os tratamentos realizados foram os seguintes: 'Hawaii 7996'-'Santa Clara' (HW-SC); 'Hawaii 7996'-'Santa Cruz Kada' (HW-SCK); 'Hawaii 7996'-'Débora Plus' (HW-DP); Pé-franco 'Santa Clara' (Testemunha); Péfranco 'Santa Cruz kada' (Testemunha); Pé-franco 'Débora Plus' (Testemunha).

Aos 13 dias após a enxertia, foi realizado o transplante das mudas enxertadas e dos pés-francos (com 42 dias após semeadura) para o campo, utilizando o espaçamento de $1,0 \mathrm{~m}$ entre fileiras duplas, 0,80 m entre linhas dentro da parcela e 0,50 $\mathrm{m}$ entre plantas dentro da linha, com sistema de plantio em quicôncio. O experimento foi desenvolvido em Latossolo Amarelo álico Distrófico, sendo a correção do solo realizada 60 dias antes do plantio, com $500 \mathrm{~kg} \mathrm{ha}^{-1}$ de calcário dolomítico. Como adubação de plantio foram utilizados, $1 \mathrm{~L}$ de esterco de gado, $14 \mathrm{~g}$ de sulfato de amônio, $150 \mathrm{~g}$ de superfosfato simples e $2 \mathrm{~g}$ de cloreto de potássio, por cova de plantio. Cada planta recebeu a seguinte adubação de cobertura: $130 \mathrm{~g}$ de sulfato de amônio e $15 \mathrm{~g}$ de cloreto de potássio, fracionados em cinco aplicações, a cada 15 dias após o transplantio. 
A irrigação por gotejamento foi feita duas vezes por dia. Para manutenção da umidade, proteção do solo e controle da emergência de plantas daninhas, utilizou-se como cobertura morta folhas secas de mangueira. Adotou-se a condução das plantas em haste única, tutorando-se verticalmente com auxílio de varas de 2,0 m de altura e o amarrio foi feito com fitilho. As brotações laterais foram retiradas à medida que surgiam.

Não foi utilizado o controle fitossanitário com produtos químicos, devido ao plantio ter sido realizado próximo a uma área de cultivo orgânico. Adotou-se o controle físico com o uso de armadilhas luminosas e o controle cultural por meio da catação manual de frutos e folhas atacados.

Com o objetivo de uniformizar o número de frutos por inflorescência foi feito o raleamento deixando apenas seis frutos, para todos os tratamentos. A capação foi realizada quando a haste principal atingiu a altura do arame, acima da $6^{\mathrm{a}}$ inflorescência, deixando três folhas acima.

Para a avaliação do desenvolvimento das plantas enxertadas foram analisadas as seguintes características: a) diâmetro do caule $(\mathrm{mm})$ em três posições ( $2 \mathrm{~cm}$ abaixo do ponto da enxertia, no ponto da enxertia e $2 \mathrm{~cm}$ acima); b) altura das plantas do colo ao ponteiro e distância do ponto de enxertia ao ponteiro $(\mathrm{cm})$, em três épocas (no dia do transplante 13 dias após enxertia e aos 40 e 80 dias após o transplante); c) altura da primeira inflorescência e distância média entre inflorescências aos 40 dias após o transplante. Para as plantas pés-francos foram avaliadas as seguintes características: a) altura das plantas $(\mathrm{cm})$ do colo ao ponteiro; b) altura da primeira inflorescência $(\mathrm{cm})$ e distância média entre inflorescências $(\mathrm{cm})$, aos 40 dias após o transplante. Os diâmetros e as alturas foram estimados utilizandose paquímetro digital de $150 \mathrm{~mm}$ e trena de 3 metros, respectivamente.

Para a avaliação da produtividade foram coletados os frutos comercializáveis (diâmetro $=40$ $\mathrm{mm}$ ) e determinada a massa média do fruto, o número e a massa total de frutos por parcela.

Os dados foram submetidos à análise de variância, sendo as médias comparadas pelo teste de Tukey, a 5\% de probabilidade, utilizando o programa estatístico SAS - Statistical Analysis System (SAS INSTITUTE INC., 2000).

\section{RESULTADOS E DISCUSSÃO}

A porcentagem de pegamento das mudas enxertadas no viveiro foi de $93,4 \%$ para todos os enxertos ('Santa Clara', 'Santa Cruz Kada' e 'Débora
Plus'), concordando com os dados obtidos por CHOE (1989) que, trabalhando com pimentão, observou que a enxertia pelo método tipo fenda pode atingir sucesso da ordem de $93 \%$ de pegamento. Neste trabalho, em condições de campo, a percentagem de pegamento foi de $98 \%$ para todos os enxertos.

Apesar de as cultivares utilizadas como enxerto terem fenótipos peculiares, não foram observadas diferenças significativas em seu desenvolvimento, quanto aos diâmetros do caule, com exceção da combinação 'HW7996' - 'Santa Cruz Kada', com menor diâmetro $(2 \mathrm{~cm}$ acima do ponto da enxertia), no dia do transplante. Contudo, essa diferença não foi observada nas avaliações realizadas aos 40 e 80 dias após o transplante (Tabela 1). Destaca-se que os valores de diâmetro do caule obtidos no transplante diferiram daqueles aos 40 e 80 dias depois, demonstrando o desenvolvimento dos enxertos até 40 dias. Já a avaliação aos 80 dias não diferiu significativamente dos valores obtidos aos 40 dias (Tabela 1). Por meio dessas observações nota-se que, para a característica diâmetro do caule até $2 \mathrm{~cm}$ acima do ponto da enxertia, as avaliações após 40 dias do transplante podem ser dispensáveis.

Segundo GonzÁlez (1999), os sintomas de baixo índice de sobrevivência das plantas enxertadas, amarelecimento das folhas, desfoliação e falta de crescimento, enrolamento das folhas, morte imediata da planta, crescimento excessivo do ponto de enxertia e ruptura do ponto de enxertia, indicam a incompatibilidade entre porta-enxerto e enxerto. Nenhum desses sintomas foi observado nas plantas enxertadas, obtendo-se bom desenvolvimento, não havendo, portanto, incompatibilidade entre o portaenxerto 'HW7996' e os enxertos ('Santa Clara', 'Santa Cruz Kada' e 'Débora Plus').

No ponto do enxerto nasceram raízes adventícias, devido à capacidade do caule do tomateiro de emiti-las em condições de alta umidade. Essas raízes morreram logo após a retirada das plantas da condição de câmara úmida e aparentemente não houve prejuízo ao desenvolvimento das plantas.

No transplante para o campo, apenas três plantas (num total de 150 plantas enxertadas) morreram devido à quebra no ponto de enxertia. $\mathrm{O}$ tutoramento das plantas deve ser feito no momento do transplante, para que o peso da copa não cause seu tombamento no ponto de enxertia.

Entre as plantas enxertadas, as avaliações da altura do ponto de enxertia ao ponteiro, também indicam desenvolvimento semelhante para todos os tratamentos (sugerindo não haver interação 
significativa entre época de avaliação e tratamento), exceto em 'Santa Clara' que na avaliação aos 40 dias após o transplante, observou-se desenvolvimento significativamente mais baixo em relação à 'Santa Cruz Kada' e 'Débora Plus' (Tabela 2). Essas observações comprovam que todas as copas tiveram compatibilidade com o porta-enxerto.

Com relação à altura das plantas do colo ao ponteiro, na avaliação realizada no dia do transplante, observou-se menor crescimento das plantas enxertadas, quando comparadas aos pés-francos. Esse fato já era esperado devido ao estresse da enxertia, processo que envolve corte e cicatrização de diversos tecidos, incluindo tecido cambial. Contudo, as plantas enxertadas atingiram um crescimento semelhante ao dos pés-francos após o transplante (avaliados aos 40 e 80 dias), à exceção do pé-franco Santa Cruz Kada que teve maior desenvolvimento em relação à combinação híbrido 'HW7996'-'Santa Cruz Kada', aos 40 dias após o transplante (Tabela 3).
As plantas enxertadas foram mais precoces na emissão da primeira inflorescência, o que pode ter ocorrido devido a alterações no equilíbrio hormonal.

No entanto, a distância entre as inflorescências foi maior em relação aos pés-francos, com exceção da combinação HW7996-SC e a cultivar Santa Clara (Tabela 3). Essas alterações podem ter ocorrido, devido ao período longo em que os pésfrancos permaneceram no viveiro, aguardando o pegamento das plantas enxertadas para serem transferidos para o campo, passando um pouco do estágio ideal de transplante (em torno de 28 dias de emergência). MARTINS (1992), trabalhando com tomateiro em campo, obteve para altura da primeira inflorescência e distância entre inflorescências, respectivamente, valores de $36,7 \mathrm{~cm}$ e $15,7 \mathrm{~cm}$ para 'Santa Clara' e 50,9 cm e 14,1 cm para 'Santa Cruz Kada'e Carvalho (2002), em ambiente protegido, obteve 41,02 cm e 27,22 cm para a cv. Débora Max.

Tabela 1. Diâmetro do caule (mm) de tomateiro das combinações híbrido ‘Hawaii 7996'-‘Santa Clara' (HW-SC), 'Hawaii 7996'-'Santa Cruz Kada' (HW-SCK), 'Hawaii 7996'-`Débora Plus' (HW-DP), no transplante (13 dias após a enxertia), e aos 40 e 80 dias após

\begin{tabular}{|c|c|c|c|c|c|c|c|c|c|}
\hline \multirow{2}{*}{ Tratamentos } & \multicolumn{3}{|c|}{$2 \mathrm{~cm}$ abaixo do enxerto } & \multicolumn{3}{|c|}{ No ponto do enxerto } & \multicolumn{3}{|c|}{$2 \mathrm{~cm}$ acima do enxerto } \\
\hline & $\mathrm{T}^{*}$ & 40 & 80 & $\mathrm{~T}^{*}$ & 40 & 80 & $\mathrm{~T}^{*}$ & 40 & 80 \\
\hline HW - SC & $6,45 a$ & $10,20 \mathrm{a}$ & $10,74 a$ & $9,24 a$ & $15,93 a$ & $15,94 \mathrm{a}$ & $5,86 a$ & $11,73 a$ & $11,73 a$ \\
\hline HW - SCK & $6,37 a$ & $10,19 a$ & $10,53 a$ & $8,92 \mathrm{a}$ & $16,00 \mathrm{a}$ & $16,06 a$ & $4,97 \mathrm{~b}$ & $11,61 \mathrm{a}$ & $11,77 \mathrm{a}$ \\
\hline HW - DP & $6,46 a$ & $10,51 \mathrm{a}$ & $10,54 \mathrm{a}$ & $9,24 \mathrm{a}$ & $16,07 \mathrm{a}$ & $16,55 \mathrm{a}$ & $5,60 \mathrm{a}$ & $11,94 \mathrm{a}$ & $12,35 \mathrm{a}$ \\
\hline Médias & $6,43 \mathrm{~B}$ & $10,30 \mathrm{~A}$ & $10,61 \mathrm{~A}$ & $9,14 \mathrm{~B}$ & $16,00 \mathrm{~A}$ & $16,12 \mathrm{~A}$ & $5,47 \mathrm{~B}$ & $11,76 \mathrm{~A}$ & $11,95 \mathrm{~A}$ \\
\hline CV (\%) & 2,66 & 3,90 & 5,36 & 3,22 & 4,72 & 3,34 & 4,60 & 6,23 & 6,52 \\
\hline
\end{tabular}

* T - No transplante.

Médias seguidas de mesma letra maiúscula na linha e minúscula nas colunas, não diferem entre si pelo teste de Tukey a 5\% de probabilidade.

Tabela 2. Altura do ponto de enxertia ao ponteiro (cm) de tomateiro das combinações híbrido 'Hawaii 7996'-'Santa Clara' (HWSC), 'Hawaii 7996'-'Santa Cruz Kada' (HW-SCK), 'Hawaii 7996'-'Débora Plus' (HW-DP) no dia do transplante (13 dias após enxertia), 40 e 80 dias após

\begin{tabular}{lccc}
\hline \multirow{2}{*}{ Tratamentos } & \multicolumn{3}{c}{ Altura da enxertia ao ponteiro } \\
\cline { 2 - 4 } & \multicolumn{1}{c}{$\mathrm{T}$} & $40 \mathrm{DAT}$ & $80 \mathrm{DAT}$ \\
\cline { 2 - 4 } 'HW 7996' -'SC' & $10,43 \mathrm{a}$ & $91,36 \mathrm{~b}$ & $132,54 \mathrm{a}$ \\
'HW 7996' - 'SCK' & $12,18 \mathrm{a}$ & $103,58 \mathrm{a}$ & $151,83 \mathrm{a}$ \\
'HW 7996' -'DP' & $10,98 \mathrm{a}$ & $103,75 \mathrm{a}$ & $139,54 \mathrm{a}$ \\
\hline Médias & $11,20 \mathrm{C}$ & $99,57 \mathrm{~B}$ & $141,31 \mathrm{~A}$ \\
\hline CV (\%) & 11,54 & 4,82 & 9,52 \\
\hline
\end{tabular}

T - No transplante. DAT - Dias após o transplante.

Médias seguidas de mesma letra maiúscula na linha e minúscula nas colunas, não diferem entre si, pelo teste de Tukey a $5 \%$ de probabilidade. 
Tabela 3. Altura da planta (AP) no transplante e aos 40 e 80 dias após, altura da primeira inflorescência (API) e distância entre inflorescências (DEI) aos 40 dias após transplante de tomateiros enxertados ('Hawaii 7996'-'Santa Clara' (HW-SC), 'Hawaii 7996'-'Santa Cruz Kada' (HW-SCK), 'Hawaii 7996'-'Débora Plus' (HW-DP) e pés-francos ('Santa Clara', 'Santa Cruz Kada' e Débora Plus')

\begin{tabular}{|c|c|c|c|c|c|}
\hline \multirow{2}{*}{ Tratamentos } & \multicolumn{3}{|c|}{$\mathrm{AP}$} & \multirow{2}{*}{$\begin{array}{c}\text { API } \\
40 \text { DAT }\end{array}$} & \multirow{2}{*}{$\begin{array}{c}\text { DEI } \\
40 \mathrm{DAT}\end{array}$} \\
\hline & $\mathrm{T}$ & $40 \mathrm{DAT}$ & $80 \mathrm{DAT}$ & & \\
\hline & & & $\mathrm{cm}$ & & \\
\hline HW7996 -'SC' & $27,02 \mathrm{c}$ & 106,72 c & $147,65 \mathrm{~b}$ & $46,33 \mathrm{~d}$ & $19,16 \mathrm{ab}$ \\
\hline HW7996 - 'SCK' & $29,02 \mathrm{c}$ & $120,22 \mathrm{bc}$ & $165,83 a b$ & $75,75 \mathrm{c}$ & 27,41 a \\
\hline HW7996 -'DP' & $28,09 \mathrm{c}$ & $118,42 \mathrm{bc}$ & $154,28 \mathrm{~b}$ & $44,43 \mathrm{~d}$ & $21,01 \mathrm{a}$ \\
\hline 'Santa Clara' & $39,48 \mathrm{~b}$ & $111,56 \mathrm{c}$ & $155,68 \mathrm{ab}$ & $111,56 \mathrm{~b}$ & $10,84 \mathrm{bc}$ \\
\hline 'Santa Cruz Kada' & 45,98 a & 137,02 a & 177,02 a & 137,02 a & $9,52 \mathrm{c}$ \\
\hline 'Débora Plus' & $36,36 \mathrm{~b}$ & $127,76 \mathrm{ab}$ & $164,54 \mathrm{ab}$ & 127,76 a & $9,79 \mathrm{c}$ \\
\hline CV $(\%)$ & 5,72 & 5,79 & 6,94 & 8,92 & 26,11 \\
\hline
\end{tabular}

T - No transplante. DAT - Dias após o transplante.

Médias seguidas de mesma letra maiúscula nas colunas, não diferem entre si, pelo teste de Tukey a $5 \%$ de probabilidade.

A colheita iniciou-se aos 43 dias após o transplante para o campo, nos tratamentos 'HW 7996' - 'Santa Clara', 'HW7996' - 'Débora Plus', 'Santa Clara' e 'Débora Plus' e aos 48 dias para os tratamentos 'HW7996' -'Santa Cruz Kada' e 'Santa Cruz Kada'. Apesar de ter havido diferença significativa entre as plantas enxertadas e pés-francos quanto à altura da primeira inflorescência, a enxertia não afetou a precocidade das cultivares, quanto à produção de frutos.

Em relação ao número de frutos, não houve diferença significativa entre os tratamentos, devido à prática cultural de capação da planta e ao raleamento da penca, o que limitou o número de inflorescências e de frutos (Tabela 4).
A produção total e a massa média de frutos não diferiram estatisticamente para os tratamentos enxertados em relação a seus respectivos pés-francos, demonstrando, assim, que o processo de enxertia não causou redução na produção (Tabela 4). Apenas para a cultivar Santa Clara foi observada maior massa média do fruto, em relação aos pés-francos 'Santa Cruz Kada', 'Débora Plus' e a combinação 'HW7996''Santa Cruz Kada'. A massa média do fruto da cv. Santa Clara $(95,15 \mathrm{~g})$ também foi superior ao observado por MARTINS (1992), em cultivo no campo (53 g). Em relação ao 'Débora Plus', a massa média do fruto $(79,12 \mathrm{~g})$ foi inferior à encontrada por Carvalho (2002), para o 'Débora Max' (89,05 g), em cultivo protegido. Esses resultados confirmam que os dados de produtividade variam muito em função das condições de cultivo.

Tabela 4. Número de frutos totais (NFT), massa média do fruto (MMF) e produtividade comercial (P) de tomateiros enxertados ('Hawaii 7996'-`Santa Clara' (HW-SC), 'Hawaii 7996'-'Santa Cruz Kada' (HW-SCK), 'Hawaii 7996'-`Débora Plus' (HW-DP) e pés-francos ('Santa Clara', 'Santa Cruz Kada' e Débora Plus')

\begin{tabular}{lccc}
\hline Tratamentos & NFT & MMF & $\mathrm{P}^{(1)}$ \\
\cline { 2 - 4 } 'HW 7996' -'SC' & $44,40 \mathrm{a}$ & $85,96 \mathrm{ab}$ & $\mathrm{tha}^{-1}$ \\
'HW 7996' - 'SCK' & $41,20 \mathrm{a}$ & $78,89 \mathrm{~b}$ & $13,98 \mathrm{ab}$ \\
'HW 7996' -'DP' & $50,80 \mathrm{a}$ & $81,04 \mathrm{ab}$ & $12,18 \mathrm{~b}$ \\
'Santa Clara' & $64,20 \mathrm{a}$ & $95,15 \mathrm{a}$ & $15,20 \mathrm{ab}$ \\
'Santa Cruz Kada' & $40,60 \mathrm{a}$ & $71,92 \mathrm{~b}$ & $22,18 \mathrm{a}$ \\
'Débora Plus' & $61,20 \mathrm{a}$ & $79,12 \mathrm{~b}$ & $11,08 \mathrm{~b}$ \\
\hline CV (\%) & 29,74 & 9,74 & $18,13 \mathrm{ab}$ \\
\hline
\end{tabular}

$\left.{ }^{1}\right)$ Dados calculados para um hectare.

Médias seguidas de mesma letra nas colunas não diferem entre si pelo teste de Tukey a 5\% de probabilidade. 
A baixa produtividade obtida neste experimento (Tabela 4) ocorreu devido às condições fitossanitárias das plantas sem o uso de controle químico, o que as predispôs às pragas e doenças. Baixas produtividades também foram encontradas por Martins (1992), em campo, obtendo 5,32 $\mathrm{t} \mathrm{ha}^{-1}$ para 'Santa Clara' e 9,71 t ha ${ }^{-1}$ para 'Santa Cruz Kada'. No entanto, Loos et al. (2002) obtiveram, em plantio protegido, produtividade de 67,94 $\mathrm{t} \mathrm{ha}^{-1}$ para 'Santa Clara' e 65,12 tha ${ }^{-1}$ para 'Débora'. Os mesmos autores, avaliando dois porta-enxertos (Anchor e BGH 3472), obtiveram variações na produtividade para 'Débora' e 'Santa Clara', quando comparados os pés-francos com as plantas enxertadas.

A cultivar Santa Cruz Kada, tanto enxertada como na forma de pé-franco, foi bastante sensível ao estresse provocado pelos diversos fatores climáticos do período de avaliação, apesar da adoção de irrigação por gotejamento com dois turnos de regas diários. Nas plantas enxertadas e em pés-francos ocorreu modificação na sua arquitetura, como folhas encarquilhadas e muitos brotos laterais. Além disso, observaram-se nos frutos rachaduras provocadas, possivelmente, pela maior sensibilidade à variação de umidade do solo. Essas mudanças na sua fisiologia podem ter refletido negativamente na produção e no peso médio dos frutos (Tabela 4).

Na combinação 'HW 7996' - 'Santa Cruz Kada' e o pé-franco 'Santa Cruz Kada' houve desenvolvimento e produção semelhantes. Portanto, as alterações no desenvolvimento das plantas não foram devido à incompatibilidade entre o portaenxerto e o enxerto, mas possivelmente à menor adaptação dessa cultivar às condições agroecológicas do verão no município de Cruz das Almas, BA.

Observou-se no campo, a incidência de murcha bacteriana nos tratamentos 'Santa Clara' (30 \%), 'Santa Cruz Kada' (20 \%) e Débora Plus (10 \%), proveniente de infestação natural por se tratar de área de produtor hortícola, onde se cultivam diversas espécies de solanáceas e cucurbitáceas. Nos tratamentos enxertados não houve incidência de murcha bacteriana, devido ao porta-enxerto ser resistente a essa doença (JAUNET E WANG, 1999).

Este trabalho demonstrou a compatibilidade entre o híbrido Hawaii 7996 (porta-enxerto resistente à murcha bacteriana) e os genótipos comerciais Santa Clara, Santa Cruz Kada e híbrido 'Débora Plus' (suscetíveis à murcha bacteriana), sem afetar negativamente o desenvolvimento e a produtividade das plantas. Foi demonstrada também, a viabilidade de produção de tomates comerciais em área infestada com $R$. solanacearum, utilizando-se o processo de enxertia em porta-enxerto resistente.

\section{CONCLUSÕES}

1. O híbrido 'Hawaii 7996' foi compatível com as cultivares comerciais 'Santa Clara', 'Santa Cruz Kada' e 'Débora Plus'; nos tratamentos enxertados houve desenvolvimento semelhante.

2. A enxertia com o híbrido 'Hawaii 7996' não afetou a produção dos frutos, em relação aos pésfrancos.

3. Na enxertia com o híbrido 'Hawaii 7996', observou-se potencial para viabilizar a produção de tomateiros comerciais suscetíveis, em áreas infestadas com $R$. solanacearum.

\section{AGRADECIMENTOS}

Ao produtor hortícola, Sr. José Augusto Coutinho Cardoso, por ter cedido a área para realização do experimento.

Ao Dr. Jaw-Fen Wanga pelo fornecimento das sementes do híbrido Hawaii 7996, do Asian Vegetable Research and Development Center (AVRDC), em Taiwan.

Ao Sr. Arildo Mariano Rego, da Empresa Seminis (SVS DO BRASIL SEMENTES LTDA), pelo fornecimento de sementes de tomate $\mathrm{cv}$. Santa Clara.

\section{REFERÊNCIAS}

ALMEIDA, O.A. Informações meteorológicas do CNP: Mandioca e Fruticultura Tropical. Cruz das Almas: EMBRAPA-CNPMF, 1999. 35p. (EMBRAPA-CNPMF. Documentos, 34).

CAÑIZARES, K.A.L. Produção de hortaliças em ambiente protegido: condições subtropicais.In: GOTO, R.; TIVELLI, S.W. (Org.). A cultura do pepino. 1.ed. São Paulo: UNESP, 1998. p.195-223.

CAÑIZARES, K.A.L.; GOTO, R. Evaluación de tres métodos de injerto em pepino tipo japonés. In: CONGRESO PANAMEÑO 1 E CONGRESO IBEROAMERICANO DE APLICACIÓN DE LOS MATERIALES PLÁSTICOS EM LA AGRICULTURA, 1., 1999, Ciudad de Panamá. Anales... Madrid: CEPLA-Comité Español de Plásticos em la Agricultura, 1999. p.140-145.

CARDOSO, S.C. Controle da murcha bacteriana do tomateiro com a incorporação de guandu e crotalária ao solo e com enxertia em porta-enxerto resistente. 2004. 72f. Dissertação (Mestrado em Ciências Agrárias / Fitotecnia). Universidade Federal da Bahia, UFBA, Cruz das Almas. 
CARVALHO, L.A. Comportamento de cultivares de tomate de crescimento indeterminado (Lycopersicon esculentum Mill.), em ambiente protegido. 2002. 96f. Tese (Doutorado em Agronomia / Fitotecnia). Escola Superior de Agricultura Luiz de Queiroz, USP, Piracicaba.

CHOE, J.S. Phytophthora blight of green pepper in Korea. Taiwan: Aspac, Food Fertilizer Technology Center, 1989. p.1825. (Extension Bulletin, 302)

GÓMEZ, A.M. Injerto de hortalizas. Valência: Generalitat Valenciana, 1997. 88p. (Divulgación técnica, 40)

GONZÁLEZ, J. El injerto en hotalizas. In: VILARNAU, A.; GONZÁLEZ, J (Eds.). Planteles: semilleros, viveros. Réus: Ediciones de Horticultura, 1999. p.121-128.

JAUNET, T.X.; WANG, J.F. Variation in genotype and aggressiveness of Ralstonia solanacearum race 1 isolated from tomato in Taiwan. Phytopathology, v.89, p.320327,1999

KAWAIDE, T. Utilization of rootstocks in cucurbits production in Japan. Japan Agricultural Research Quarterly, Ibaraki, v.18, p.248-249, 1985.

LIMA, M. S.; VERDIAL, M. F.; MINAMI, K.; TESSARIOLI NETO, J. Avaliação de porta-enxertos para pepino japonês. Scientia Agrícola, Piracicaba, v.57, n.1, p.169-172, 2000.

LOOS, R.A.; SILVA, D.J.H. DA; RIBEIRO, E.H. Avaliação do efeito de enxertia na produção de tomateiro em ambiente protegido. Horticultura Brasileira, Brasília, v.20, n.2, julho, 2002. Suplemento 2. CD-ROM.
LOPES, C.A. Ecologia de Pseudomonas solanacearum. In: TALLER SOBRE ENFERMIDADES BACTERIANAS DE LA PAPA, 1, 1994, Brasilia. Memórias... Brasília: Centro Nacional de Pesquisa de EMBRAPA/Hortaliças, 1994. p.17-22.

LOPES, C. A.; SANTOS, J. R. M. DOS. Doenças do tomateiro. Brasília: Embrapa-SPI/ Embrapa-CNPH, 1994. 61p.

MARTINS, G. Uso de casa de vegetação com cobertura plástica na tomaticultura de verão. 1992. 65f. Tese (Doutorado em Agronomia / Produção Vegetal), Faculdade de Ciências Agrárias e Veterinárias, Universidade Estadual Paulista, Jaboticabal.

PEIL, R.M. A enxertia na produção de mudas de hortaliças. Ciência Rural, Santa Maria, v.33, n.6, p.1169-1177, 2003.

REIFSCHNEIDER, F.J.B.; TAKATSU, A. Pseudomonas solanacearum no Brasil: aspectos macroepidemiológicos. Fitopatologia Brasileira, Brasília, v.10, n.2, p.123, 1985.

SAS INSTITUTE INC. SAS/STAT User's Guide. v.8.0. v.1. Cary NC: SAS Institute, Inc., 2000.

SILVEIRA, N.S.S.; MARIANO, R.L.R.; MICHEREFF, S.J. Pseudomonas solanacearum no Brasil. Summa Phytopathologica, Jaboticabal, v.22, n.2, p.97-111, 1996.

TAKATSU, A.; SILVA, C.B.; REIFSCHNEIDER, F.J.B. Variabilidade e distribuição de Pseudomonas solanacearum de solanáceas nas diferentes regiões do Brasil. Fitopatologia Brasileira, Brasília, v.9, n.2, p.387, 1984.

YAMAKAWA, K. Use of rootstocks in Solanaceous fruitvegetable production in Japan. Japan Agricultural Research Quarterly, Ibaraki, v.15, n.3, p. 175-180, 1982. 